\title{
LOS SASTRES EN LOS PROCESOS DE FE DEL TRIBUNAL DE DISTRITO DE LA INQUISICIÓN DE TOLEDO (1483-1597)
}

\author{
TAILORS IN THE PROCESSES OF FAITH IN THE \\ INQUISITION COURT OF TOLEDO (1483-1597)
}

\author{
ALICIA MARCHANT RIVERA \\ Universidad de Málaga
}

Resumen: El objetivo del presente artículo es iniciar una serie de estudios de conjunto sobre el gremio de los sastres, quienes, en la investigación histórica más reciente, han sido objeto de perspectivas particulares referidas a zonas geográficas concretas de la Península Ibérica. El escoger los años comprendidos entre 1483 y 1597 , fecha del primero y último de los procesos inquisitoriales contra sastres estudiados en este trabajo, un total de 73, obedece al cambio cualitativo que se produce en el Tribunal de la Inquisición en esta etapa, además de ser el fondo del Tribunal local de Toledo, junto con el de Cuenca y Valencia, el único que se conserva con información de causas anteriores a 1560. Se examinará el colectivo de sastres procesados por judaizantes, luteranos o moriscos; las proposiciones heréticas, las blasfemias y las palabras escandalosas en las causas esgrimidas contra sastres, para concluir con las inhabilitaciones y los delitos sexuales de bigamia. Todo ello nos desvelará nuevas coordenadas respecto a este colectivo, como el hecho de que aprovecharan circunstancias socio-económicas favorables para medrar, que al paralelo del oficio de sastre desempeñaran otras profesiones anejas, o incluso el acercamiento a otros círculos buscando significación y distinción social.

Palabras clave: Sastres, Inquisición, Tribunal de Toledo, siglos XV-XVI.

\begin{abstract}
The aim of the present article is to initiate a series of studies about tailors, who, in the most recent historical investigation, have been an object of particular perspectives referred to geographical concrete zones of the Iberian Peninsula. To choose the years between 1483 and 1597 , dates of the first and last one of the inquisitorial processes against tailors studied in this work, a total of 73 , obeys to the qualitative change that takes place in the Inquisition Court in this stage; moreover the documents from the local Court of Toledo, beside those of Cuenca and Valencia, are the only ones that remain with information about causes previous to 1560 . We will examine the group of tailors processed for Jewish, Lutheran or Muslims; the heretical propositions, the blasphemies and the scandalous words in the processes against tailors, to conclude with the incapacitations and the sexual crimes of bigamy. All this will reveal new coordinates with regard to this group: they were taking advantage of favourable socio-economic circumstances to grow, incor-
\end{abstract}


porating other attached professions, or even the intention of belonging to certain circles looking for significance and social distinction.

Key words: Tailors, Inquisition, Toledo, 15 th and 16th centuries.

\section{PRELIMINARES*.}

Establecer el porqué de la elección del gremio de sastres para iniciar una serie de estudios que se inaugura con un monográfico sobre sastres e Inquisición tiene una motivación muy nítida: la necesidad de proyectar un estudio de conjunto sobre este colectivo gremial, que en la investigación histórica más reciente ha sido objeto de interesantes perspectivas particulares. Así, como botón de muestra, podemos reseñar que se ha sometido a examen su funcionamiento social, profesional y económico en ciudades como Zaragoza y Burgos a lo largo del siglo $\mathrm{XV}^{1}$, en el territorio valenciano durante la Edad Moderna $^{2}$, la Málaga de los albores de la misma época ${ }^{3}$, el Madrid del siglo XVII ${ }^{4}$ u horquillas cronológicas más abiertas para otros puntos geográficos peninsulares como Santiago de Compostela ${ }^{5}$. Sus parámetros de religiosidad colectiva han visto la luz en ciudades como Sevilla y Jaca $^{6}$. A lo que se añaden variados detalles acerca de la legislación que los regía ${ }^{7}$,

*AHN (Archivo Histórico Nacional).

${ }^{1}$ M. I. FALCÓN PÉREZ, "Sobre la industria del vestido en Zaragoza en el siglo XV: las ordenanzas de la cofradía de sastres, calceteros y juboneros", Aragón en la Edad Media, 12 (1995), pp. 241-266.

J. D. GONZÁLEZ ARCE, "De la corporación al gremio. La cofradía de sastres, jubeteros y tundidores burgaleses en 1485”, Studia historica. Historia medieval, 25 (2007), pp. 191-219.

2 R. SANCHIS LLORENS, "El offici de sastres y calcetters de Alcoy", en Primer Congreso de Historia del País Valenciano: celebrado en Valencia del 14 al 18 de abril de 1971, vol. 3, Valencia, 1976, pp. 201-208.

R. DE LA PUERTA, "Los avatares del asociacionismo de los artífices del vestir en la Valencia Moderna", en L. PRATS (coord.), Estudios en homenaje a la Profesora Teresa Puente, vol. 2, Valencia, 1996, pp. 481-495.

${ }^{3}$ V. CARRETERO RUBIO, La artesanía textil y del cuero en Málaga (1487-1525), Málaga, Cedma, 1996.

${ }^{4}$ J. C. ZOFÍO LLORENTE, "Reproducción social y artesanos. Sastres, curtidores y artesanos de la madera madrileños en el siglo XVII", Hispania: Revista española de Historia, 71/237 (2011), pp. 87-120.

${ }^{5}$ F. BOUZA BREY, "Historia de la cofradía gremial de sastres de Santiago de Compostela", Revista Compostellanum, 7 (1962), pp. 569-620.

6 J. F. HALDÓN REINA, "Aproximación histórico-artística a la antigua Hermandad de Nuestra Señora de los reyes del gremio de sastres", en J. RODA PEÑA (coord.), II Semana de estudios Medievales, Nájera, 2009, pp.155-190.

J. GESTOSO PÉREZ Y M. FERNÁNDEZ GÓMEZ, Noticia histórico-descriptiva del antiguo pendón de la ciudad de Sevilla y de la bandera de la Hermandad de los sastres, Sevilla, Área de Cultura, 1999. 
las relaciones de género en el seno gremial ${ }^{8}$, así como su fortuna paremiológica ${ }^{9}$. Como ya se ha advertido, el presente estudio será el primero de una serie que pretende abordar diversos aspectos de este colectivo gremial sobre un amplio espectro del territorio peninsular, desde la segunda mitad del siglo XV hasta finales del siglo XVI: sastres procesados por la Inquisición, sastres y relación con la nobleza en su dimensión profesional, sastres y pasajes a Indias, comportamiento social, relación con la justicia y funcionamiento gremial.

El escoger los años comprendidos entre 1483 y 1597 , fecha del primero y último de los procesos contra sastres estudiados en este trabajo, un total de setenta y tres, obedece al cambio cualitativo que se produce en el Tribunal de la Inquisición en esta etapa, teniendo en cuenta que el periodo de más intensa actividad del aparato inquisitorial tiene lugar en la horquilla 1480-1530. Además de ser el fondo del Tribunal Local de Toledo, junto con el de Cuenca ${ }^{10}$ y Valencia ${ }^{11}$, el único que se conserva con información de causas anteriores a 1560, comienza a formarse en 1482 y extiende su documentación hasta el siglo XIX ${ }^{12}$. Un fondo cohesionado que ha contado con un proceso de catalogación progresivo y adecuado ${ }^{13}$.

M. GÓMEZ DE VALENZUELA, "La regla de la cofradía jaquesa de sastres, bajo la advocación de San Lorenzo (1602)", Argensola: Revista de CC. Sociales del Instituto de Estudios Altoaragoneses, 113 (2003), pp. 315-328.

7 J. BALEZTENA ABARRATEGUI, "Ordenanzas contra los sastres que tuvieren paños faltosos (1533)", Cuadernos de etnología y etnografia de navarra, 74 (1999), pp. 563-570.

${ }^{8}$ R. REGUERA RAMÍREZ, “Costureras versus sastres. También una cuestión de género", El Pajar: Cuaderno de etnografía canaria, 25 (2008), pp. 110-116.

${ }^{9}$ R. MONNER SANS, De sastres: entretenimiento paremiológica, Talleres de la Casa Jacobo Peuser, 1909.

${ }^{10}$ V. SÁNCHEZ GIL, "El Tribunal de la inquisición de Cuenca: notas para un catálogo de sus miembros (1489-1714)", Archivo Ibero-Americano, 157 (1980), pp. 3-36.

11 R. GARCÍA CÁRCEL, Orígenes de la Inquisición española: el Tribunal de Valencia, 1478-1530, Barcelona, 1985.

12 R. GONZÁLEZ CASTRILLO, "El ingeniero militar Jerónimo de Borja, prisionero del Santo Oficio", Hispania, 50/174 (1990), 93-113.

${ }^{13}$ M. GARCÍA-ARENAL, "Los moriscos de la región de Cuenca según los censos establecidos por la Inquisición en 1589 y 1594”, Hispania, 38 (1978), 151-202.

Un primer trabajo de catalogación y descripción de sus fondos, con un soporte y volumen de quinientos legajos, siete libros y dos expedientes, fue el realizado por Vicente Vignau en su obra Catálogo de las causas contra la fe seguidas ante el tribunal del Santo Oficio de la Inquisición de Toledo, y de las informaciones genealógicas de los pretendientes a oficios del mismo (Madrid, Tip. de la Revista de archivos, bibliotecas y museos, 1903; reeditado por Nabu Press en el 2011). Los instrumentos de descripción contemplados en el inventario dinámico del AHN para este fondo a fecha 30 de junio de 2002 son: Índice de informaciones genealógicas, manuscrito, en fichas; N. MORENO GARBAYO, y M ${ }^{\mathrm{a}}$ VERGARA DONCEL, Archivo Histórico Nacional. Sección de Inquisición. Guía sumaria, Madrid, 1978 (Portal PARES). Paradójicamente, la edición de Vignau no se conserva en España (ni Biblioteca Nacional, ni Catálogo Colectivo del Patrimonio Bibliográfico), es el vol. 7883 del Harvard College Library Preservation microfilm program 2001. El origi- 
Atendiendo a las clasificaciones más extendidas respecto a la agrupación temática de causas inquisitoriales ${ }^{14}$, se examinará el colectivo de sastres procesados por judaizantes, luteranos o moriscos; las proposiciones heréticas, las blasfemias y las palabras escandalosas en las causas esgrimidas contra sastres; las inhabilitaciones y los delitos sexuales focalizados en la bigamia.

\section{SASTRES JUDAIZANTES.}

La primera y más amplia causa de denuncia inquisitorial que afecta al colectivo de sastres sería la de delitos contra la fe; y es bajo este epígrafe que se aglutinan los procesos a sastres por judaizantes. El cronista de los Reyes Católicos Andrés Bernáldez, en su referencia a los judíos cuando estos se encaminaban al destierro en 1492, prefiguró el tópico y la imagen que se tenía acerca de las actividades socio-profesionales de los mismos, tópico que se ha mantenido en vigor hasta casi el momento actual. Bajo esta óptica, los judíos se adscribían a los arriendos, la usura, el comercio; ejercían oficios como sastres, tejedores, zapateros; rechazaban el trabajo duro y vinculado a la tierra. Pero lo cierto es que variados estudios tradicionales han contribuido a desmontar este tópico, presentando a los judíos en una suerte de profesiones variadas, del mismo modo que estas se llevaron a cabo en el contexto de la sociedad cristiana.

No obstante, como ocurrió por ejemplo en Sevilla a lo largo del siglo XV, el mayor número de artesanos judíos pertenecía al subsector textil, desempeñando en el ramo desde oficios primarios como el de tejedor de lienzos o tundidor hasta el de sastre.

Entre los judíos de la ciudad de Palencia abundaron los sastres. Datos que también se documentan para la zona catalana. En lugares como la villa castellonense de Onda, la platería y la sastrería fueron las actividades básicas de los judíos durante el siglo XV. Algunas urbes de la Península contaron con una desarrollada artesanía judía, tal fue el caso de Zaragoza, Valencia y Barcelona. Los artesanos y las corporaciones de oficios cristianas llegaron a ver en ellos a posibles

nal procede de la University of Michigan y fue digitalizado el 17 de febrero de 2009, con una extensión de 697 páginas, cuyo índice es el siguiente: Prólogo (6), Deshonestidad (72), Hechicería (81), Alumbrados (104), Herejía Calvinistas (111), Ilusos (123), inhábiles (140), intrusos (154), libros prohibidos (235), palabras escandalosas (255), perjurio (287), religiosos casados (304), solicitantes (330) apéndice y México.

${ }^{14}$ J. P. DEDIEU, L'administration de la Foi: l'Inquisition de Tolède XVIe-XVIIIe siècle, Madrid, 1992.

C. MORES ROS, "La actividad del Tribunal de la Inquisición en Barcelona entre 1759 y 1786", Pedralbes: Revista d'Historia Moderna, 8/2 (1988), pp. 503-512. 
competidores y desarrollaron hacia el colectivo un sentimiento fuerte de hostilidad. Esto aconteció por ejemplo con los sastres, situación que condujo a la emisión de normas restrictivas hacia los artesanos judíos por parte de las autoridades municipales cristianas. En relación a la proporción de artesanos sastres, pueden ofrecerse datos para zonas como Calatayud, donde había un $25 \%$ de sastres, un $20 \%$ de zapateros y un $10 \%$ de tejedores. En algunas aljamas los sastres alcanzaron niveles mucho mayores, como en Daroca, donde el colectivo representó el $50 \%{ }^{15}$.

Antes de la expulsión de los judíos en España en 1492 tienen lugar los primeros procesos contra judaizantes. Aunque hacia esta fecha, y ya desde época anterior, en algunas ciudades ya no había judería, ya se van advirtiendo destellos de criptojudaísmo. Se trata más bien de la prosecución de tradiciones y costumbres de carácter doméstico que se seguían perpetuando, sin reconocerse en ellas connotaciones de tipo herético. Entre las acusaciones más frecuentes a los judaizantes se hallaban la de celebrar el Yom Kipur, día de la expiación o del gran perdón, una de las grandes solemnidades del calendario judío después de diez días de penitencia; la acusación de guardar el Sabbat, la de hacer proselitismo, el no observar fiestas establecidas por la Iglesia católica, o hacer pervivir costumbres como la de derramar agua después de la muerte de alguna persona cercana. Las testificaciones de la acusación procedían generalmente de vecinos e incluso de parientes, desvelándose en el fondo una problemática de tipo social: los testimonios encubrían un subfondo de conatos y rencillas inherentes a la convivencia vecinal. Estas desavenencias, en opinión de M. J. Ferrero, nacen en última instancia de un problema económico que probablemente sea la primera piedra que desencadene la acción que culmina con el proceso ${ }^{16}$.

En los procesos de fe del Tribunal de la Inquisición de Toledo, entre los años 1483 y 1597, hallamos dieciséis procesos de fe contra sastres, los menos contra familiares suyos, por judaizantes. Entre ellos se documentan cinco que se incoan antes de que se produzca la expulsión de los judíos, concretamente los procesos de fe de Diego el Pintor (1484) ${ }^{17}$ y Juan de Chinchilla $(1483)^{18}$, sastres de

${ }^{15}$ J. HINOJOSA MONTALVO, "La sociedad y la economía de los judíos en Castilla y la Corona de Aragón durante la Baja Edad Media", en J. I. DE LA IGLESIA DUARTE (coord.), II Semana de Estudios Medievales, Nájera, 1992, pp. 79-110.

${ }^{16}$ M. J. FERRERO RODRÍGUEZ, "Una judaizante procesada por el Tribunal de la inquisición: Cuenca, 1490”, Helmantica, 142-143 (1996), pp. 237-247.

Ver también J. CONTRERAS, “La Inquisición en Galicia y la minoría conversa: un análisis sociológico del judaizante gallego", Estudios de historia social, 20-21 (1982), pp. 429-445.

${ }^{17}$ Inquisición, AHN, legajo 165, exp. 1. 
Ciudad Real; los procesos de Juan de Cáceres (1486) ${ }^{19}$ y Juan Chapatel $(1486)^{20}$, sastres y vecinos de Toledo, y el proceso de fe de Alonso González de Mesa, sastre e hijo del también sastre Pedro González, residente en la villa de Guadalupe $(1485)^{21}$. En los procesos que se inician en la primera mitad del siglo XVI, es frecuente ver en el epígrafe junto al patronímico del acusado la aposición "cristiano nuevo de judío", aludiendo a los nuevamente convertidos. Tal fue el caso de Juan Núñez ${ }^{22}$, sastre de Toledo, a quien se acusa de judaizante en 1521; el del sastre Pedro de Jerez ${ }^{23}$, sastre en Cadalso (Cáceres), al que se le inicia proceso en 1513, o el del sastre de Talavera de la Reina Bartolomé Gallego ${ }^{24}$, a quien se le inicia su proceso por judaizante en 1525. Al margen de las ya expresadas, el resto de las procedencias geográficas de los sastres sometidos a procesos de fe por judaizantes adscritas al Tribunal de la Inquisición de Toledo fueron: Belvís, tierra del conde de la Leytosa, Atienza, Granada, Guadalajara, Alcalá de Henares y Uceda.

Entre los sastres condenados a procesos por judaizantes hallamos algunos que combinaban su actividad profesional textil con otras de naturaleza diversa. Así en lo referente a Juan Martín de Aguilar ${ }^{25}$, que fue sastre, labrador y cardador, vecino de Belvís, actual anejo de Villanueva de San Carlos, en la provincia de Ciudad Real, zona de tradicional predominio de la actividad agrícola y ganadera en pleno Campo de Calatrava, lo que justificaría su dedicación al laborío del campo y al cardado de la lana ${ }^{26}$. O el sastre de Atienza (Guadalajara) Benito de Herre$\mathrm{ra}^{27}$, quien a la sazón combinaba su actividad sartorial con la de tendero, ecos de la prosperidad de la que gozaría la villa hasta el siglo XV, en el que llegó a contar con catorce iglesias además de un castillo, murallas y torres defensivas. Por la etapa en la que se inicia el proceso contra Isabel de Águila, mujer del sastre Benito de Herrera (1540), Atienza había perdido importancia al dejar de ser ciudad estratégica y fronteriza y en ella la antaño floreciente actividad mercantil langui-

\footnotetext{
${ }^{18}$ Inquisición, AHN, legajo 140, exp. 8.

${ }^{19}$ Inquisición, AHN, legajo 138, exp. 3.

${ }^{20}$ Inquisición, AHN, legajo 140, exp. 6.

${ }^{21}$ Inquisición, AHN, legajo 153, exp. 5.

${ }^{22}$ Inquisición, AHN, legajo 171, exp. 2.

${ }^{23}$ Inquisición, AHN, legajo 158, exp. 13.

${ }^{24}$ Inquisición, AHN, legajo 150, exp. 1.

${ }^{25}$ Inquisición, AHN, legajo 131, exp. 11.

${ }^{26}$ F. JIMÉNEZ DE GREGORIO, "Belvís de la Jara: de lugar a villa", Cuaderna: revista de estudios humanísticos de Talavera y su antigua tierra, 7-8 (1999-2000):149-169.

${ }^{27}$ Inquisición, AHN, legajo 131, exp. 7.
} 
deció en beneficio de otras rutas ${ }^{28}$. Singular es también el caso de Diego de Acos$\mathrm{ta}^{29}$, vecino de Uceda (Guadalajara), condenado por judaizante en 1535, que ejercía en la villa como sastre y procurador. Actividad que no extraña si tenemos en cuenta que bajo el poder real Uceda adquirió verdadera importancia como cabecera de una extensa comarca, el denominado "Común de la villa y Tierra de Uceda", compuesto por 19 aldeas. A finales del s. XIV empezaron a surgir pleitos a causa de las lindes y el aprovechamiento de pastos, leñas y aguas con los señoríos limítrofes, que conducen a que la villa empiece a perder parte de su territorio, hasta consumarse su venta en 1609, por las deudas ocasionadas por los pleitos, a Cristóbal Gómez de Sandoval, duque de Lerma ${ }^{30}$. Al igual que Isabel del Águila ${ }^{31}$, fueron en este periodo otras las mujeres de sastres condenadas por la Inquisición por judaizantes. Es el caso de Elvira González ${ }^{32}$, vecina de Guadalajara, esposa del sastre Juan de Sigüenza, en el año 1493. Esto nos hace entrever que los sastres, que ejercían profesiones liberales, estaban ávidos de aprovechar circunstancias socio-económicas favorables para medrar, tal y como convenía al talante del artesano judío cuyo tópico ya se había perpetuado, razón por la que ejercían otras actividades profesionales de naturaleza diversa, como se ha visto, que combinaban al alimón con la actividad sartorial. Esta última, la que los definía e incardinaba gremialmente, implicaba en ocasiones un trabajo y dedicación intensos que contravenía, por lo general, normativas cristianas como la de las fiestas de guardar. Descendamos para examinar esta cuestión con más detalle a los hitos del proceso del sastre Juan Núñez, cristiano nuevo de judío y vecino de Toledo.

Juan Núñez, de edad de cuarenta y cuatro o cuarenta y cinco años, casado con Catalina, de dieciséis o diecisiete, también conversa, había pasado a la ciudad de Fez en Marruecos cuando se produjo la expulsión general de los judíos. Allí permaneció durante un año para regresar más tarde a Los Palacios (Sevilla), donde recibió el bautismo. Su padre se había convertido al cristianismo y vivió en Talavera de la Reina, siendo sepultado en el Monasterio de la Trinidad. Por el contrario, su madre había seguido viviendo en Fez como judía, junto a tres hermanas suyas. En el momento de su declaración, Juan Núñez tiene cuatro hijas y

\footnotetext{
${ }^{28}$ N. ÁVILA SEOANE, "El Señorío de los Silva de Cifuentes en los concejos de Atienza y Medinaceli (1471-1779)", Revista de Historia Moderna: Anales de la Universidad de Alicante, 24 (2006), pp. 395-436.

${ }^{29}$ Inquisición, AHN, legajo 131, exp. 1.

${ }^{30}$ M. M. MARTÍN GALÁN, "Crisis de la comunidad rural y señorío: el caso de Uceda", Mélanges de la Casa de Velázquez, 29/2 (1993), pp. 217-230.

${ }^{31}$ Inquisición, AHN, legajo 131, exp. 7.

${ }^{32}$ Inquisición, AHN, legajo 153, exp. 16.
} 
dos hijos, la mayor de ellos, Juana, con dieciséis años. Alega que en su oficio de sastre ha trabajado muchos sábados por la noche con sus oficiales y también vísperas de fiestas y algunos días de Pascuas, todo ello por acabar algunas ropas que corrían prisa. A lo que añade que un día de Todos los Santos había cortado un capuz para un capitán apellidado Guzmán. De igual modo había comido carne en Cuaresma por estar enfermo de bubas, con licencia. A Juan Núñez se le castiga con la Excomunión mayor y "perdimiento y confiscación” de todos sus bienes. Lo relajan al brazo secular para que sea tratado benigna y piadosamente, y no se le aplica pena de muerte ni mutilación ni efusión de sangre. Como era habitual, el Tribunal declararía inhábiles a los descendientes, impidiendo que pudieran ocupar cargos públicos — en línea masculina hasta el segundo grado, y en la femenina, hasta el primero- ${ }^{33}$.

\section{SASTRES LUTERANOS Y MORISCOS.}

Con la carta que el Emperador Carlos V dirigía a su hija, la regenta doña Juana, casada con Manuel de Portugal, con fecha de 25 de mayo de 1558, comienza en la historia intelectual y religiosa de España el ataque contra la "Reforma", o la "secta de Lutero". El antiguo monarca le previene en ella de la intención revoltosa de los luteranos, tanto contra la fe católica, como contra el estado político. Luego, el Santo Oficio arremetió contra los grupos luteranos de Sevilla y Valladolid y tuvo lugar el proceso del arzobispo Carranza, procesos que se condujeron bajo la dirección de Fernando de Valdés, Inquisidor General, y el apoyo del papa Pablo IV. En los años siguientes a la ofensiva papal y estatal contra la "secta" protestante, fueron muchos los particulares, españoles o extranjeros, que recibieron de la Inquisición la etiqueta de luterano. Se trató también de un tipo de xenofobia, tanto social como religiosa, ya que el luteranismo que perseguía el Santo Oficio era más sociológico que religioso ${ }^{34}$. Así, como ejemplo, el Tribunal cordobés del Santo Oficio, entre el 10 de febrero de 1555 y el mes de diciembre de 1594, procesaba a treinta y cuatro personas por "palabras sospechosas luteranas" o "por cosas de la secta de Lutero" 35 .

\footnotetext{
${ }^{33}$ Inquisición, AHN, legajo 171, exp. 2.

34 J. PUELL DE LA VILLA, "El silencio se ha impuesto: la herejía luterana en el Tribunal del Santo Oficio de la inquisición de Toledo. El proceso del doctor Sigismundo Arquer (15631571)", Anuario jurídico y económico escurialense, 23 (1991), pp. 307-348.

${ }^{35}$ J. H. EDWARDS, "La inquisición y la Reforma: los luteranos y los anglicanos ante los tribunales, 1550-1600”, en J. PRADELLS NADAL y J. R. HINOJOSA MONTALVO (coords.),
} 
Pentecoste Clas, de profesión sastre y natural de Comarte (Inglaterra), es procesado por el Tribunal Inquisitorial de Toledo en el año 1596, por anglicano ${ }^{36}$. Otros sastres, naturales de Francia y avecindados en Toledo y ciudades cercanas, también fueron procesados por luteranismo en estas mismas fechas. Entre ellos, Pedro Savanés, natural de Poitiers y residente en Toledo, proceso que se cierra en 1554 ${ }^{37}$; Juan Borgoñón, sastre y calcetero de la ciudad de Beçançon, nacido en Borgoña pero vecino de Madrid, contra el que la Inquisición arremete en 1566, acusado de apostasía y luteranismo ${ }^{38}$; y el sastre Francisco Robert, francés, vecino de Madrid $^{39}$, a quien en 1569 se le inicia el proceso de fe por luterano.

Veamos con más detalle el expediente del primero de ellos, el sastre Pentecoste Clas ${ }^{40}$. En el momento de su declaración — que precisa de intérprete-, Pentecoste Clas tiene cuarenta y un años. Relata que había convivido con sus padres hasta los veinte años, tiempo en el cual había aprendido el oficio de sastre, oficio que había ejercido en diversos lugares de Inglaterra. Ya como hombre casado, cuando obtenía algún caudal extraordinario, viajaba hasta la Península para adquirir géneros, en concreto al Puerto de Vizcaya. Posteriormente abandonó el oficio de sastre para meterse a soldado de la mar, oficio en el que permaneció durante dieciséis años. En una de sus incursiones marítimas, la tripulación perdió el timón en el fragor de una tormenta, siendo apresados por los franceses, quienes les robaron y los dejaron perdidos en el mar. Al arribar al puerto de Asturias, la Justicia los tomó presos, aunque lograron salir gracias a la intercesión de dos religiosos irlandeses. Se les conduce entonces a Valladolid, donde recibieron instrucción en temas de fe, instrucción a la que ponía colofón el interrogatorio en cuestión. Pentecoste Clas relata que, al quedar huérfano de padre, se ocupó de su formación religiosa su madre, que era católica, pero añade que habían de practicar a escondidas porque sufrían persecución. Su madre le había enseñado el Ave María, el $\mathrm{Pa}$ ter Noster y el Credo en latín, oraciones por las que se le pregunta con éxito en el interrogatorio. Añade el sastre soldado que no se ha confesado porque no le han enseñado. De igual modo atribuye a la ignorancia y a la falta de costumbre la abstinencia de comer carne. Se acuerda pues que se le admita a reconciliación en

1490, El umbral de la modernidad: el Mediterráneo europeo y las ciudades en el tránsito de los siglos $X V$-XVI vol. 1, Valencia, 1994, pp. 437-446.

J. CONTRERAS, "The impact of Protestantism in Spain, 1520-1600 “, en S. HALICZER (ed. y trad.), Inquisition and society in early Modern Europe, London, 1987, pp. 47-63.

${ }^{36}$ Inquisición, AHN, legajo 108, exp. 2.

${ }^{37}$ Inquisición, AHN, legajo 110, exp. 5.

${ }^{38}$ Inquisición, AHN, legajo 111, exp. 5.

${ }^{39}$ Inquisición, AHN, legajo 112, exp. 9.

${ }^{40}$ Inquisición, AHN, legajo 108, exp. 2. 
forma, sin hábito ni cárcel ni confiscación de bienes, imponiéndole algunas penas espirituales a su arbitrio, siempre que se garantice su instrucción en los temas principales de la fe católica.

Por otro lado, se conservan en Cuenca (Archivo Diocesano Conquense) alrededor de 500 procesos incoados a moriscos entre 1515 y 1630, y varios censos y listas de los que habitaban los distritos del Tribunal conquense. En estos censos establecidos por la Inquisición en 1589 y 1594 se documenta que la principal ocupación que mantenían profesionalmente era la de esclavos, criados, braceros o jornaleros del campo ${ }^{41}$. Cuando aparecen dedicaciones profesionales vinculadas al oficio sartorial, como tejedora de lienzos, o costureras, suelen ocuparlas las féminas. No obstante, y ya en el Tribunal de Toledo, entre los años 1533 y 1534, se documenta el proceso de fe por morisca dirigido contra Inés de Viana, mujer del sastre Juan Riquelme, vecinos de Aldea del Rey ${ }^{42}$; y en el año 1582 se inicia el proceso de fe por morisco contra Micael Rizo Carcandil, natural de la ciudad de Atenas, que profesaba el oficio de sastre. En este último caso la cuestión morisca se confunde con la xenofobia ${ }^{43}$. Es el propio pintor Doménikos Theotokópoulos, más tarde de sobrenombre El Greco, natural de la ciudad de Candia y vecino de Toledo, el que actúa de intérprete en la audiencia para Micael Rizo en la mañana del 1 de mayo de 1582.

Por esa época, Micael Rizo Carcandil era aprendiz de sastre y contaba con unos dieciséis o diecisiete años, no estaba casado ni tenía hijos. Es natural de Atenas $\mathrm{y}$, tras declarar su genealogía, afirma que el padre vive, su madre es difunta y tiene sólo una hermana que vive en la ciudad de Atenas. Micael Rizo fue bautizado de pequeño en la ciudad de Atenas, pero con diez o doce años fue conducido junto a unos mil muchachos a Constantinopla, donde lo hicieron turco a la fuerza. Aunque más tarde obtuvo la bendición del Papa en Roma y llegó a besar a $\mathrm{Su}$ Santidad, de lo cual tiene testimonio. En su declaración no recuerda con seguridad haber recibido el sacramento de la confirmación, pero se signa, santigua y profiere las cuatro oraciones básicas del católico cristiano en griego, bien dichas, ya que se las había enseñado su madre. Añade incluso que, desde que vino de Roma y ya en

${ }^{41}$ M. GARCÍA-ARENAL, "Los moriscos de la región de Cuenca según los censos establecidos por la Inquisición en 1589 y 1594”, Hispania, 38 (1978), pp. 151-202.

B. VINCENT, "Los moriscos y la Inquisición (1563-1630)", Chronica Nova: Revista de Historia Moderna de la Universidad de Granada, 13 (1982-1983), pp. 197-206.

I. PÉREZ DE COLOSÍA RODRÍGUEZ, "El Norte de África, destino de los moriscos perseguidos por la Inquisición”, Aldaba: revista del Centro Asociado a la UNED de Melilla, 26 (1995), pp. 367-379.

${ }^{42}$ Inquisición, AHN, legajo 198, exp. 17.

${ }^{43}$ Inquisición, AHN, legajo 196, exp. 30. 
la ciudad de Toledo, ha oído misa en la Compañía de Jesús, gracias a la ayuda de Ferdinando, intérprete que había venido con él desde dicha ciudad. Al parecer, Micael Rizo Carcandil había sido denunciado por un tal Nicolás, que fue criado de Demetrio Focas, personaje con quien el joven Micael Rizo había realizado su periplo por varias ciudades italianas, entre ellas Florencia, hasta llegar a España, donde pretendía ir a Santiago de Compostela y hacerse fraile. El criado Nicolás había mantenido varias peleas públicas con su amo, Demetrio Focas, razón por la que lo acusa de turco y por extensión a Carcandil. Este último alega en defensa de Demetrio Focas que "si se ha lavado la parte posterior del asiento" es porque tiene una fístula, y que la manera de rezar alzando y bajando la cabeza es a la manera no de los turcos sino de los griegos católicos cristianos. El final del proceso dictamina la absolución del joven Carcandil, lo que se constituye en exponente del carácter de advertencia que animaba gran parte de este tipo de procesos.

\section{PROPOSICIONES HERÉTICAS, BLASFEMIAS Y PALABRAS ESCANDALOSAS EN LOS PROCESOS A SASTRES.}

Los casos de judaísmo, en la época que reflejamos, constituyeron un principal objetivo del Tribunal Inquisitorial. Más adelante, los casos de judaísmo dejarían de ser frecuentes y la Inquisición se ocuparía de otro tipo de delitos, como es el caso de las proposiciones heréticas, es decir, enunciados que resultaban a todas luces contrarios a cualquiera de las afirmaciones asumidas como verdades católicas y definidas como cuestiones de fe, uno de los principales motivos de acusación a lo largo del siglo XVIII ${ }^{44}$. Las más frecuentes en el seno de las proposiciones heréticas fueron las relacionadas con contradecir los mandamientos de la ley de Dios, especialmente los referidos a los pecados de la carne, el sexto y el noveno. En las acusaciones por proposiciones heréticas, algunas veces encontró el Tribunal el atisbo de herejía pretendido, pero en otras ocasiones estas supuestas proposiciones heréticas sólo destilaban hilaridad, falta de cultura o señuelos de enajenación, elementos que en alguna ocasión fueron considerados como causa de atenuación, y en muchas otras permitieron a la Inquisición poner sobre aviso del

\footnotetext{
${ }^{44}$ Dedieu, para los años posteriores a 1560 hasta el final de la centuria, destaca la mayor incidencia que tuvieron los delitos que él engloba bajo el epígrafe de Palabras, término en el que incluye los delitos de blasfemia, palabras escandalosas, proposiciones heréticas, erróneas u otros delitos cometidos verbalmente y dirigidos contra la doctrina o el respeto a Dios. Estos delitos representan el 47.25\% de las causas examinadas. J. P. DEDIEU, "Les causes de foi de l'Inquisition de Tolède (1483-1820). Essai statisque”, Mélanges de la Casa de Velázquez, XIV (1978), pp. 143171.
} 
riesgo de zaherir con la palabra cuestiones de fe en las que no cabía disensión alguna. A Francisco de Pastrana, cristiano nuevo de judío, y vecino de esa localidad, en Guadalajara, se le abre proceso en 1528 por proposiciones heréticas ${ }^{45}$.

En esta misma línea de clasificación de delitos contra la fe católica, habría que apuntar que hacia la mitad del siglo XVI la Inquisición transforma el control de la disciplina religiosa de los cristianos viejos en uno de sus principales objetivos; es entonces cuando los jueces llevarán con gran celo el seguimiento de todas aquellas afrentas a la divinidad o posibles corrupciones de las verdades de la religión cristiana: se trata de las condenas por blasfemias o palabras impías. A pesar de la oposición de las otras autoridades de justicia, la Inquisición pasó a perseguir dichos recursos y a recibir jurisdicción para ello. Ahora bien, estas afirmaciones reflejaban una gradación: podían denotar una adhesión secreta a las herejías consideradas como formales (judaísmo, mahometanismo o protestantismo), como ya se ha visto, manifestar una incredulidad leve o no pasar de ser palabras escandalosas, de las que hablaremos más adelante, que revelaban cierta indisciplina religio$\mathrm{sa}^{46}$. Para el periodo cronológico establecido, se documentan nueve casos de sastres implicados en procesos de fe por blasfemia. De nuevo el ser converso de judío o de moro, o ser descendiente de judíos conversos, gravita en tres de los casos de estos procesos de fe citados. Con lo que la acusación por judaizante continúa estando estrechamente vinculada e implicada en la de blasfemia, proyectando una mayor observancia sobre los individuos citados. Este fue el caso de Fernando de Salas, platero y vecino de Córdoba, y de Fernando de Córdoba, sastre y vecino de Montilla (Córdoba), ambos descendientes de judíos conversos y procesados por blasfemias al haber argumentado que una imagen de Cristo no era sino un palo ${ }^{47}$.

${ }^{45}$ J. A. ALEJANDRE GARCÍA, "Inquisición sevillana y proposiciones heréticas: la ley de Dios y los pecados de la carne", Historia, Instituciones, documentos, 25 (1998): 1-12.

M. ASPELL DE YANZI FERREIRA, "Los Comisarios del Tribunal del Santo Oficio de la Inquisición en Córdoba de Tucumán. Las proposiciones heréticas", en F. BARRIOS PINTADO (coord.), Derecho y administración pública en las Indias hispánicas: actas del XII congreso internacional de historia del derecho indiano, vol. 1, Toledo, 1998, pp. 227-248.

Inquisición, AHN, legajo 222, exp. 6.

${ }^{46}$ M. BOEGLIN, "Blasfemia y herejía en la época moderna. Los blasfemos ante la Inquisición de Sevilla en tiempos de los Austrias", en A. CASTRO SÁNCHEZ (coord.), Franciscanos, místicos, herejes y alumbrados, Córdoba, 2010, pp. 283-304.

K. A. MYERS, “¿Testimonio para la canonización o prueba de blasfemia?: La Inquisición de Nueva España y la hagiografía de Catarina de San Juan “, en M. E. GILES (coord.), Mujeres en la Inquisición: la persecución del Santo Oficio y el Nuevo Mundo, Barcelona, 2000, pp. 326-356.

${ }^{47}$ J. CARO BAROJA, Los judios en la España Moderna y Contemporánea, vol. 1, Tres Cantos (Madrid), 2000, p. 384. 
También el del sastre Diego de Murcia, vecino de Cazalegas (Toledo) ${ }^{48}$, converso de judío, cuyo proceso de fe por blasfemia se resuelve en 1556; y de Alfonso de Soto $^{49}$, hijo de nuevo convertido de moro, de profesión sastre, natural de Ayllón y avecindado en Toledo. Los restantes sastres implicados son: Juan López de Aguilera ${ }^{50}$, de Herencia (Ciudad Real), Juan Díaz ${ }^{51}$, de Alia (Cáceres), Gonzalo López de Medina ${ }^{52}$, de Cogolludo (Guadalajara), Diego Sánchez ${ }^{53}$ (Cuerva, Toledo) y Alonso Martínez, de Villacañas ${ }^{54}$ (Toledo). Más distinguida era la situación de Bartolomé de Torres, sastre de corte, vecino de Munébrega (Zaragoza), a quien se le incoa un proceso de fe por blasfemia en el año 1538. No es de extrañar que avecindado en Munébrega, cuna de cardenales, obispos, embajadores, artistas, patria chica de Juan Fernández de Heredia, gran maestre de la Orden de San Juan de Jerusalén, el sastre Bartolomé de Torres hubiera medrado en su oficio llegando a disfrutar de prebendas profesionales, formando parte de un gremio sensible a los aspirantes con menor poder económico: las ordenanzas de 1550 de los sastres de corte eximían de derechos a los oficiales pobres que quisieran realizar su opera prima $^{55}$.

Como segunda ilustración, un vecino con el que departía el sastre Diego de Murcia en la ribera del río Alberche lo acusa de la siguiente blasfemia: habiendo muerto Lázaro fueron María y Marta a buscar al Señor y lo hallaron en un asador "comiendo unos torreznillos" y les dijo que esperaran, que después de almorzar irían a casa de Lázaro y que, tras haber llegado a la casa, Lázaro se levantó y se tiró un pedo. De esta acusación se excusa luego el sastre aludiendo a que se trataba de un cuentecillo narrado por dos labradores portugueses difuntos, y que en esa lid distendida él lo había referido - a pesar de que el testigo afirmaba que se reía con complacencia de lo narrado- Diego de Murcia también recibe la acusación de trabajar en días de fiesta, frente a lo que argumenta que un domingo después de misa había hecho un sayo a un pobre sin llevarle blanca, así como también había cosido corchetes, hecho ojetes y acabado algunas ropas para las Pascuas. De igual modo había cortado algunas ropas después de misa. Sobre el sastre Diego de Mur-

\footnotetext{
${ }^{48}$ Inquisición, AHN, leg. 42, exp. 29.

${ }^{49}$ Inquisición, AHN, legajo 47, exp. 35.

${ }^{50}$ Inquisición, AHN, legajo 39, exp. 30.

${ }^{51}$ Inquisición, AHN, legajo 34, exp. 16.

${ }^{52}$ Inquisición, AHN, legajo 39, exp. 27.

${ }^{53}$ Inquisición, AHN, legajo 46, exp. 56.

${ }^{54}$ Inquisición, AHN, legajo 40, exp. 22.

55 J. A. NIETO SÁNCHEZ, Artesanos y mercaderes: una historia social y económica de Madrid (1450-1850), Madrid, 2006, p. 138.
} 
cia gravita una pena pecuniaria, de 30 ducados, que no ha podido pagar a tiempo al no haberle dejado vender una casa.

Otros procesos se refieren, apunta Joseph Pérez, a lo que la nomenclatura del Santo Oficio denomina "palabras deshonestas", palabras escandalosas, bromas dudosas acerca de la fe, del culto y de sus ministros. En opinión de J. P. Dedieu, que abordó en su tesis las persecuciones contra los cristianos viejos en el distrito de Toledo, estas faltas no fueron consideradas muy graves por la Inquisición, que zanjaba rápidamente estos procesos imponiendo una penitencia espiritual vinculada al rezo, oraciones a las que en alguna ocasión se adhería una leve sanción económica. Cuando estas palabras deshonestas parecían indicar que sus autores dudaban de la inmortalidad del alma o de la resurrección de los muertos, o hacían profesión de materialismo, entonces sí que podían venir acompañadas de reprimendas más severas. Por el contrario, si esas palabras se proferían sin intención, podían ser excusadas más fácilmente. Tal es el caso de Catalina Zapata ${ }^{56}$, una mujer de treinta y tres años, esposa de Juan de Moya, sastre de Alcalá, que se denuncia espontáneamente a los inquisidores el veintinueve de septiembre de 1564 porque recuerda haber dicho, doce o trece años atrás, sin saber lo que decía: "No me ves en la miseria en este mundo; no me verás penando en el otro". Al escuchar el edicto de fe, se da cuenta de que ha pecado contra la fe y contra la inmortalidad del alma; el Tribunal le impone una simple reprimenda y la condena a ayunar dos viernes y a rezar cuatro veces el rosario durante la próxima semana ${ }^{57}$. Entre los sastres (o familiares de sastres) denunciados a la Inquisición del Tribunal de Toledo por palabras escandalosas a partir de 1536 se encontraron: Pedro García Hortelano, natural y vecino de Arenas (Ávila) ${ }^{58}$; Luis de Cuenca, vecino de Mondéjar (Guadalajara) ${ }^{59}$; Juana, mujer del sastre Ayras, vecina de Berraco (El Barraco, Ávila) ${ }^{60}$; Francisco García, natural de Rodilana (Valladolid) ${ }^{61}$; Antonio de Galeas, vecino de Almonacid de Zorita (Guadalajara) ${ }^{62}$; Alonso Toledano, alias el Viejo, vecino de Cebreros (Ávila) ${ }^{63}$ y Alonso de Almorox, vecino de Escalona (Toledo $)^{64}$. A esta nómina se unen los casos de dos flamencos y un francés avecindados

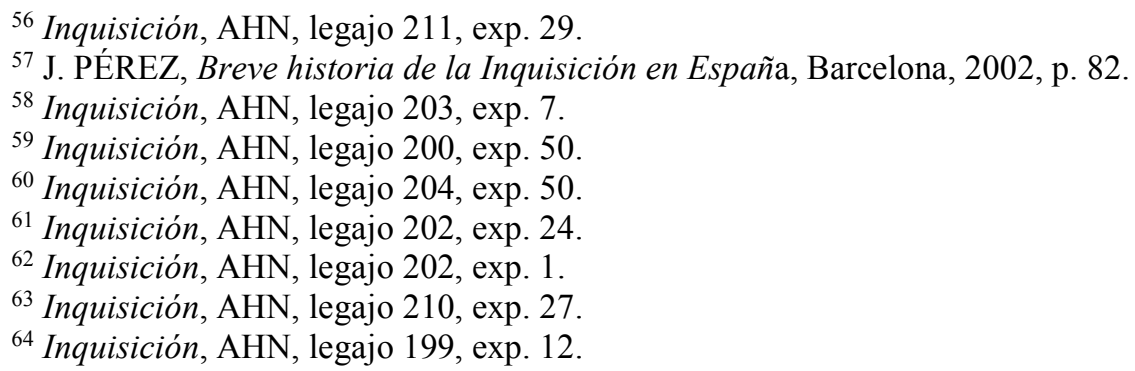


en Madrid: el sastre Nicolás Alemán, nacido en Flandes ${ }^{65}$; Magdalena, natural de Flandes, de profesión criada, esposa del sastre Tilimán, ambos vecinos de la villa de Madrid $^{66}$ y el también sastre Antonio de la Puebla o Antonio de la Popula, nacido en Francia ${ }^{67}$. Probablemente en estos tres últimos casos la acusación de palabras escandalosas también iba ligada al sentimiento de xenofobia que animó no pocas acusaciones esgrimidas ante el Tribunal de la Inquisición. Al también sastre Juan Francés, natural de Francia y residente en la localidad de Barajas, se le inicia proceso por palabras escandalosas en 1566. Juan Francés simultaneaba su oficio de sastre con el de mozo para Alonso Ramírez de Arellano ${ }^{68}$; y a Juan Jiménez, sastre, pero también criado de los frailes del Monasterio de Guadalupe, se le contempla proceso por la misma causa entre los años 1583 y $1585^{69}$. En esta misma línea de la acusación por palabras escandalosas, como ya se ha apuntado, se encuentran los procesos de fe por afirmaciones deshonestas, en los que se vieron implicados por ejemplo, el sastre Diego de Lara ${ }^{70}$, vecino de Madrid, Antón Martín, vecino de Ramacastañas, en Ávila, donde ejercía como sastre y labrador ${ }^{71} \mathrm{o}$ Alonso de Cigales, sastre, natural y vecino de Toledo ${ }^{72}$. En otras ocasiones, de la palabra se pasaba a los hechos, a los signos, surgiendo así los procesos de fe contra sastres acusados de sacrilegio. Así le sucedió a Andrés Rodríguez, natural y vecino de Montarrón (Guadalajara) ${ }^{73}$ y a Fernando de Contreras, sastre avecindado en Almagro, que cometió sacrilegio pisando en una viña una bandera con una cruz de Calatrava ${ }^{74}$.

Conozcamos más de cerca la naturaleza de estos procesos entrando con detalle en el expediente de Juan Francés, quien contaba con dieciocho años más o menos cuando lo procesan por palabras escandalosas. Su padre fue Garçón de Torián, sastre, vecino de Osert (Oseart). Su madre Luisa, difunta. No conocía abuelos maternos ni paternos ni tíos. Tenía cuatro hermanos: Nicolás - calcetero-, Pierre —zapatero-, Formán — panadero-y Luis, candelero en la misma localidad. Todos casados en esta villa ubicada cerca de París. Argumenta en su declaración no tener descendientes ni judíos ni moros, que oye misa y reza

\footnotetext{
${ }^{65}$ Inquisición, AHN, legajo 199, exp. 8.

${ }^{66}$ Inquisición, AHN, legajo 205, exp. 45.

${ }^{67}$ Inquisición, AHN, legajo 208, exp. 3.

${ }^{68}$ Inquisición, AHN, legajo 201, exp. 47.

${ }^{69}$ Inquisición, AHN, legajo 204, exp. 47.

${ }^{70}$ Inquisición, AHN, legajo 72, exp. 19.

${ }^{71}$ Inquisición, AHN, legajo 72, exp. 44.

${ }^{72}$ Inquisición, AHN, legajo 69, exp. 28.

${ }^{73}$ Inquisición, AHN, legajo 226, exp. 7.

${ }^{74}$ Inquisición, AHN, legajo 225, exp. 4.
} 
las oraciones de la Iglesia. De igual modo se persigna y reza ante el Tribunal las cuatro oraciones (Credo, Salve Regina, Padrenuestro y Avemaría). La denuncia había venido por parte de un carpintero del pueblo de Barajas que, escuchando el deseo de Juan Francés de querer marcharse a Francia, le dice al sastre que allí todos son luteranos, a lo que este replica asintiendo. Posteriormente Juan Francés argumenta que no recuerda haber dicho tal cosa. A la sazón el sastre se encontraba en casa de Ramírez de Arellano, cura de Barajas, porque estaba curando unas cabalgaduras, así como trabajando en unas labores de obra que el cura hacía. El cura alude a que siempre lo ha visto ser buen cristiano, ayunar, comulgar y que achaca lo que ha pasado a que Juan Francés pudo estar borracho o cansado de las sornas de los otros trabajadores de la obra acerca de que era luterano. En el periodo de cárcel sufre traslado al hospital y finalmente queda absuelto ${ }^{75}$.

\section{SASTRES INHABILITADOS Y BÍGAMOS.}

La inhabilitación por descendiente de condenado es otra de las causas reflejadas en los procesos de fe esgrimidos contra los sastres en la fecha por el Tribunal de la Inquisición de Toledo. Se trata del antecedente inmediato de la limpieza de sangre, que tendría un papel central en la mecánica social desde mediados del siglo XVI en adelante, y que llegaría a significar la ausencia de antepasados musulmanes, judíos o herejes. La presencia en la ascendencia cercana de un hereje condenado llevaba implícitas ciertas inhabilitaciones que ahora examinaremos. No obstante, los reconciliados, hijos y nietos de condenados seguían accediendo a todos los cargos que les estaban teóricamente vetados, mediante la compra de una dispensa de la autoridad que prohibía. En 1495 los delegados de los "reconciliados, hijos y nietos de relajados de Toledo y su arzobispado" pidieron a los Inquisidores de la ciudad "que las penitencias y penas arbitrarias....les fueran conmutadas a otras pecuniarias", petición que fue producto de una negociación llevada a cabo en la Corte. Del pago de estas penas pecuniarias se beneficiaron el fisco real y la Inquisición, que lo empleó fundamentalmente en las restituciones de confiscaciones indebidas. A través de las escasas cartas de habilitación conservadas, se observa que la dispensa se refería mayormente al conjunto de las limitaciones al lujo: vestir seda, llevar oro y plata, armas y andar a caballo. Pero también se referían al hecho de portar el sambenito o al arrendamiento de rentas. Otro asunto

\footnotetext{
${ }^{75}$ Inquisición, AHN, legajo 201, exp. 47.
} 
sería el de las inhabilidades que disponía el derecho común pontificio, que seguían vigentes a pesar de la habilitación ${ }^{76}$.

Hallamos cinco procesos de inhabilitaciones por descendientes de condenados en los que se ven implicados sastres, y concretamente tres de ellos afectan a vecinos de Daimiel. La comunidad de moriscos daimieleña estaba asentada en el "Barrio Nuevo", al pie del castillo, alrededor de San Juan, su antigua mezquita. En 1502 los antiguos mudéjares de las cinco Villas del Campo de Calatrava se convirtieron a la fe de Cristo. De modo que entre los años de 1538 y 1550 la Inquisición de Toledo juzgó a unos sesenta falsos conversos, de los más de cuatrocientos moriscos que moraban en la villa; no murió ninguno, pero el Islam fue total y definitivamente aniquilado en Daimiel. Después de 1545 fueron regresando los reconciliados y condenados a cárcel perpetua, siendo conmutada la pena por otras penitencias espirituales, sobre todo a los más influyentes y a las esposas de cristianos viejos ${ }^{77}$. En este contexto se inicia en 1532 el proceso de fe de Álvaro de Olivares, que era sastre de paños avecindado en Daimiel, junto con el de sus hijos Pedro y Juan, también residentes en Daimiel, acusados de montar a caballo, llevar armas y usar seda, plata y oro, contraviniendo las pragmáticas que les inhabilitaban para llevar tales prendas, en calidad de hijos y nietos de Juan de Olivares, que había sido condenado por herejía ${ }^{78}$. Otra acusación que trasciende las prohibiciones referidas al decoro y la suntuosidad es la que afecta en 1573 a otro miembro de la familia, Diego de Olivares, sastre avecindado en la villa de Daimiel, por desacatar las pragmáticas y leyes que, como nieto de condenado por el Santo Oficio, le inhabilitaban para ejercer los oficios de mayordomo, procurador y alcalde de cofradías, oficios que había desempeñado conjuntamente con el de sas$\operatorname{tre}^{79}$. En ese mismo año a otro sastre, Mateo Ramírez, natural del Corral de Almaguer y vecino de Daimiel, se le abre el proceso de fe por inhábil al ser nieto de Juan de Valencia, que había sido condenado por la Inquisición ${ }^{80}$. Al sastre de Almodóvar Juan de Alcocer, se le incoa proceso de fe por inhábil, al contravenir las disposiciones a las que estaba sujeto al ser descendiente de procesados por la In-

${ }^{76}$ J. P. DEDIEU, "Herejía y limpieza de sangre: la inhabilitación de los herejes y sus descendientes en España en los primeros tiempos de la inquisición ", en Á. DE PRADO MOURA (coord.), Inquisición y sociedad, Valladolid, 1999, pp. 139-156.

77 S. GARCÍA- VELASCO Y MARTÍN DE ALMAGRO, Historia de Daimiel, Madrid, 1987.

${ }^{78}$ Inquisición, AHN, legajo 119, exp. 53.

${ }^{79}$ Inquisición, AHN, legajo 119, exp. 54.

${ }^{80}$ Inquisición, AHN, legajo 120, exp. 2. 
quisición ${ }^{81} \mathrm{y}$, finalmente, Catalina Hernández, vecina de Manzanares, mujer del sastre Marcos Fernández, es denunciada ante la Inquisición por llevar una saya de terciopelo, desacatando así las pragmáticas y leyes que, al ser nieta de condenado por hereje, le inhabilitaban para poder hacerlo ${ }^{82}$.

En el ámbito del derecho penal canónico, bígama es la persona consagrada al servicio de Dios que contrae matrimonio, o el casado que se ordena in sacris sin el consentimiento de la mujer, o, en tercer lugar, la persona que celebra dos o más matrimonios al mismo tiempo, esto es, en vida del cónyuge anterior. A los ojos de la doctrina jurídica bajomedieval la bigamia fue un delito de fuero mixto, el que podían atender tanto la jurisdicción secular como la canónica en función de la prioridad cronológica: el tribunal que conocía primero el delito seguía hasta el final el procedimiento. No obstante, durante la Edad Moderna, el delito de bigamia va a vincularse a una jurisdicción canónica especial, la del Tribunal del Santo Oficio de la Inquisición. Así, durante siglos, los bígamos serán procesados y, ocasionalmente, condenados, por incurrir en sospecha de fe, y no por los perjuicios jurídicos o económicos que su conducta pudiera ocasionar en el ámbito social y familiar $^{83}$. Esta es la esencia del proceso contra el sastre Juan García, natural y vecino de El Corral de Almaguer, que es procesado en 1549 por bigamia ${ }^{84}$. Como ofensa a la Iglesia y menosprecio del sacramento del matrimonio, se había casado con la hija de un vecino del Romeral "por mano de clérigo", consumando el enlace. Viviendo la primera esposa, se casó por segunda vez en la Villa de San Clemente, también con bendición eclesiástica y consumando el matrimonio. Empleó diversos nombres para evitar ser reconocido, unas veces Juan García y otras veces Gonzalo Hernández. Durante la acusación lo consideran hereje apóstata de la santa fe católica. Él lo confiesa y reconoce todo e incluso añade precisiones: que había contraído la primera vez matrimonio en Mondéjar y luego se había casado en Monreal por segunda vez. Al ser allí descubierto, se fue a la Calzada de Calatrava

\footnotetext{
${ }^{81}$ Inquisición, AHN, legajo 119, exp. 5.

${ }^{82}$ Inquisición, AHN, legajo 119, exp. 34

${ }^{83}$ E. GACTO, "El delito de bigamia y la Inquisición española", Anuario de Historia del Derecho Español, LVII (1987), pp. 465-492.

Ver también: M. TORRES AGUILAR, "Algunos aspectos del delito de bigamia en la Inquisición de indias", Revista de la Inquisición: (intolerancia y derechos humanos), 6 (1997), pp. 117 138.

J. C. GALENDE DÍAZ, "La Inquisición borbónica toledana: su intervención en las causas de bigamia”, Cuadernos de estudios manchegos, 17 (1987), pp. 43-67.

C. CALDERÓN, "Un siglo de transgresiones: el delito de bigamia en la Galicia del s. XVIII según papeles de la Inquisición”, Fundación, 5 (2001-2002), pp. 373-394.

${ }^{84}$ Inquisición, AHN, legajo 25, exp. 3.
} 
a trabajar de su oficio de sastre, y allí se casó la tercera vez estando vivas las otras dos mujeres. De la Calzada pasó a Daimiel y de allí a la villa de San Clemente; estando en San Clemente tuvo noticia del fallecimiento de su primera mujer; asimismo supo que la segunda esposa se había trasladado al Romeral, a la cual fue a buscar y le comentó que la primera mujer había muerto y fue allí donde concertaron casarse públicamente. Luego volvió a la villa de San Clemente, donde se desposó por cuarta vez. Juan García alega que él nunca se llegó a cambiar el nombre, sino que tenía un compañero que se llamaba Gonzalo Hernández y que a veces lo llamaban así a él, por error. El acusado reconoce íntegramente su culpa. En la sentencia, además de la confiscación de bienes, se ordena que salga como penitente en cuerpo con una vela entre las manos y soga al cuello y corona en la cabeza y que se ponga en el cadalso, en lugar donde pueda ser visto. Allí estaba previsto que abjurase públicamente de la dicha sospecha de herejía. Del mismo modo recibiría doscientos azotes por las calles de la ciudad a voz de pregonero que publicara la causa del castigado. Finalmente, también se le condena a servir en las galeras de su Majestad por un tiempo de cinco años consecutivos. Algo más adelante, entre 1581 y 1583 , se lleva a cabo el proceso de fe contra el también sastre Benito de Vinegra, natural de San Millán de la Cogolla (La Rioja) y vecino de Guadarrama (Madrid), por delito de bigamia ${ }^{85}$. En la otra vertiente reconocida para el delito de bigamia, el profesar en vida del cónyuge, hallamos el caso de Francisco de la Fuente, natural de Calvarrasa de Abajo (Salamanca), sastre de oficio, que había profesado en la Orden de santo Domingo viviendo todavía Luisa de Encinas, su supuesta mujer, que moraba en la ciudad de Guadalajara. Recibe proceso de fe por bígamo entre los años 1556-1557 ${ }^{86}$.

Íntimamente relacionada con la temática sexual que estamos abordando se encuentra el caso de las posibles "desviaciones sexuales" que la Inquisición trató en procesos sonados, como el de Elena de Céspedes, alias "Eleno" de Céspedes, natural de Alhama en Granada y residente en Ocaña (Toledo), quien había sido esclava y después libre. Casada a los dieciséis años con un tal Cristóbal Lombardo, da a luz a un hijo del mismo nombre. El marido muere pronto en Baeza y Elena de Céspedes deja a su hijo a cargo de la familia Marco Antonio, de Sevilla. Cuando la Inquisición la interroga en 1587, declara que ha contraído matrimonio por segunda vez con María del Caño ante el cura de Ciempozuelos. Revela a los inquisidores que cuando murió su marido se vistió de hombre y estuvo en la gue-

\footnotetext{
${ }^{85}$ Inquisición, AHN, legajo 30, exp. 24.

${ }^{86}$ Inquisición, AHN, legajo 224, exp. 7.
} 
rra de los moriscos de Granada, se examinó después de cirujano y conseguido el título se casó con María, ejerciendo como tal en Yepes (Toledo). Lo interesante que nos hace traer este proceso a colación es que Eleno de Céspedes, antes que soldado y cirujano, en su pasado femenino, había tenido por oficio tejedora, sastre y calcetera ${ }^{87}$. Ejerce el oficio de sastre porque no puede vivir del de tejedora. Al regresar de la guerra de los moriscos, puede asentarse en Arcos de la Frontera y examinarse de sastre en Jerez. Podemos ver en Eleno de Céspedes el deseo de afirmarse socialmente y de vivir libre de necesidad. Y tiene la suerte de librarse de los gremios que en las ciudades encuadraban a los artesanos dentro de un marco institucional severo, que teóricamente no admitía a los descendientes de esclavos ni a las mujeres sino para labores ínfimas o cuando eran las viudas de los maestros. De Arcos se encamina a Marchena donde trabaja un poco más de dos años; luego está en Vélez Málaga un poco más de un año, en Alhama un año, en Archidona, en Osuna, hasta llegar luego a la Corte. Madrid representa una nueva etapa. Allí conoce a un cirujano que le enseña un nuevo oficio. Abandona entonces su oficio de sastre por el de cirujano, más lucrativo. Termina sus días azotada por las calles de Yepes y Ciempozuelos, portando las vestiduras alusivas a su delito y recluida de por vida como enfermera sin sueldo en un hospital de la localidad, adonde peregrinaban las gentes considerando su pretendido hermafroditismo como símbolo de sanación y hechicería ${ }^{88}$.

\section{CONCLUSIONES.}

En la etapa cronológica analizada, el examen de los procesos de fe esgrimidos contra sastres nos conduce a extraer las siguientes conclusiones aplicadas a un amplio espectro del territorio peninsular, aquel que abarcó la jurisdicción del Tribunal de Distrito de la Inquisición de Toledo.

El colectivo de sastres, que ejercía una profesión artesanal y liberal, estaba ávido de rentabilizar las posibles circunstancias socio-económicas favorables de los lugares donde habitaban o desarrollaban su labor profesional, para en última instancia medrar. Tal fue el caso del sastre Juan Martín de Aguilar, que combina-

${ }^{87}$ J. PÉREZ ESCOHOTADO, Sexo e Inquisición en España, Madrid, 1992, pp. 157-162.

M. C. BARBAZZA, "Un caso de subversión social: el proceso de Elena de Céspedes (15871589)", Criticón, 26 (1984), pp. 17-40.

E. MAGANTO PAVÓN, "La intervención del Dr. Francisco Díaz en el proceso inquisitorial contra Elena/o de Céspedes, una cirujana transexual condenada por la Inquisición en Toledo en 1587", Archivos españoles de urología, 60/8 (2007), pp. 873-886.

${ }^{88}$ Inquisición, AHN, legajo 234, exp. 24. 
ba su actividad con la de labrador y cardador, aprovechando así los recursos agrícolas y ganaderos en la época de la tierra de Belvís. O el del sastre Diego de Acosta, quien supo aprovechar la coyuntura en la que se sumió la villa de Uceda desde finales del siglo XIV hasta principios del XVII, con la proliferación de pleitos por la demarcación de lindes, lo que le permitió ejercer al paralelo como procurador. Igualmente procedió el sastre Benito de Herrera quien, aprovechando la prosperidad de la villa de Atienza en la etapa, simultaneaba su actividad profesional con la de tendero; o el sastre de corte Bartolomé de Torres, que supo progresar en su oficio acomodándose a las necesidades de la villa de Munébrega, a la sazón cuna de movimientos culturales y esplendor político y social, demandante pues de las diversas creaciones del arte sartorial.

La tónica habitual, como se ha podido comprobar, era que, en su deseo de mejorar, al paralelo del oficio de sastres, estos ejercieran en la época otras profesiones anejas, complementarias o más distantes de su dedicación profesional. Tal fue el caso también de Eleno de Céspedes, tejedora y calcetera en su pasado femenino, sastre tras superar el examen del oficio en Jerez de la Frontera y finalmente cirujano, oficio más lucrativo, tras afrontar también la prueba que le habilitó para ejercer dicha disciplina. $\mathrm{O}$ el de Pentecoste Clas, que abandona su oficio de sastre en Inglaterra para enrolarse como soldado de la mar.

Lo cierto es que fuera cual fuera la causa que provocara este simultanear de actividades — garantía de subsistencia, complemento de retribuciones, enriquecimiento personal—, muchas de estas situaciones venían animadas por añadidura por un deseo de búsqueda de protección y significación social, como lo evidencia el acercamiento de numerosas figuras de sastres a entornos religiosos. Así hemos tenido oportunidad de comprobarlo en el caso del sastre Juan Francés — mozo del cura de Barajas Ramírez de Arellano-, quien temporalmente curaba en su casa unas cabalgaduras y trabajaba en unas labores de obra que el cura realizaba. El sastre Juan Jiménez ejerció también como criado de los frailes del Monasterio de Guadalupe. Por su parte, el sastre daimieleño Diego de Olivares, desacatando las pragmáticas y leyes que le inhabilitaban como nieto de condenado por el Santo Oficio, llegó a ostentar los cargos de mayordomo, procurador y alcalde de cofradías, dedicaciones que había desempeñado conjuntamente con la de sastre. Al también sastre salmantino Francisco de la Fuente lo recibe como profeso la Orden de Santo Domingo aún en vida de su esposa Luisa de Encinas, razón por la que es condenado por bígamo. Y en última instancia, Micael Rizo Carcandil, que había aprendido el oficio de sastre en Atenas, manifiesta su voluntad - tras su periplo por Italia - de peregrinar a Santiago de Compostela y finalmente hacerse fraile. 
Aunque bien pudiera también interpretarse este deseo de protección y significación social, implícito en el acercamiento a círculos religiosos, como una forma de encubrimiento de prácticas religiosas propias o un deseo de eximirse de potenciales acusaciones o denuncias inquisitoriales, así como también el intento de zafarse de aquellas por las cuales se les condena en estos procesos.

Al fin y al cabo, la mayor parte de estos artesanos — entre ellos abundantes judíos, según se han examinado - no hacían sino perpetuar el tópico que cronistas de la época se encargaron de enraizar, ejerciendo actividades profesionales de mayor o menor calado que combinaban a la perfección con su dedicación sartorial. Los procesos nos dejan constancia de que esta última, la que les confería la coordenada gremial, implicaba un trabajo y una dedicación bastante intensos que contravenían, en ocasiones, normativas cristianas como la de las fiestas de guardar. Pero, en última instancia, los testimonios de los procesos solían camuflar una suerte de resquemores y disputas inherentes a la convivencia vecinal, desavenencias derivadas finalmente de un motivo económico, que probablemente fuera el punto de partida inicial. Todo ello sin olvidar el aderezo del sentimiento de xenofobia, que animó, como se ha podido comprobar, no pocas de las acusaciones esgrimidas ante este Tribunal de la Inquisición de Toledo. 